\title{
Four more years of blood, sweat and tears
}

\author{
President Obama's re-election was welcome news to many scientists - but it won't release the fiscal \\ vice that's taking a grip of US research spending.
}

The re-election of Barack Obama as president of the US was a landmark event in many ways. However, it will not alter the underlying dynamic of US research policy which is that its universities and laboratories are facing the end of a decades-long period of global dominance.

For optimists, Obama's re-election can be viewed as a victory of science and reason. The difficulties that his opponent, Mitt Romney, had with these concepts were best captured in the final stages of the election campaign itself, when many of his supporters directed their ire at the polling data (as presented by the main polling organizations, whose integrity was ultimately vindicated). That episode looked like a natural end-point of Republican flirtation with the denial of reality, and may point towards a more reasoned approach from the Grand Old Party in future.

More prosaically, the election reinstated a talented team of scientific leaders in senior administrative positions, including Nobelprize winning physicist, Steven $\mathrm{Chu}$, as energy secretary, and physicist John Holdren as Obama's chief scientific adviser. That team inspired great hopes when it was appointed in $2008^{1}$, but experienced a strangely flat first term, in which Chu, in particular, scarcely featured in national debates on energy policy and climate change.

The immediate issue for most bench scientists, however, is that of declining budgets. These are not the potentially declining budgets so often forewarned by the science lobby, but actual, year-on-year reductions in the dollars available for most disciplines. Obama's stimulus package welcome as it was - injected an extra $\$ 16$ billion into research during a period of budget stagnation, but is now falling away. According to the American Association for the Advancement of Science, spending on non-military research and development, without the stimulus money, fell from about $\$ 65$ billion in 2010 to $\$ 60$ billion in 2012 .

Worse is still to come, whatever the outcome of this winter's negotiations on the 'fiscal cliff'. And even before this decline in spending, the geographic distribution of global science was shifting rapidly away from the US. According to the Royal Society of London, for example, the US share of the global scientific literature, by volume, fell

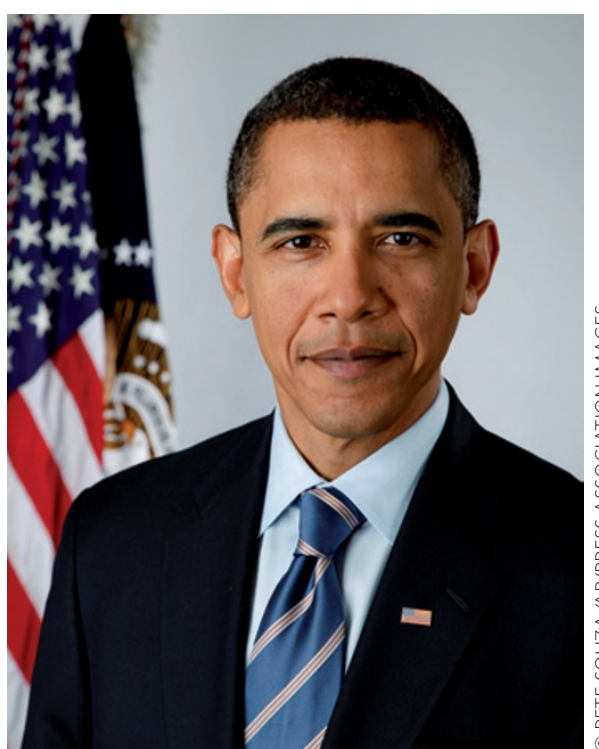

President Barack Obama's re-election cannot alter the fact that a period of US dominance over global science is coming to an end.

from $30 \%$ in 1997 to $20 \%$ in 2009 , and is projected to reach just $10 \%$ by $2020^{2}$.

Nowhere is this trend more profound than in materials science. In 1997, again using the imperfect metric of research volume, the European Union, the US and the Asia-Pacific region each contributed about 9,000 papers to this field, according to a 2011 study from Thomson Reuters ${ }^{3}$. In 2009, the US was producing about the same number of papers in this rapidly expanding field, while the EU total had grown to 13,000 and that of the Asia-Pacific region to 30,000 .

Now we know that volume isn't everything. But, as the Thomson Reuters study observed, the gap in the rate at which a typical paper is cited between the US and the Asia-Pacific nations, including China, is narrower than you might think, and is closing all the time. While politicians pay more attention to biotechnology and drug development, they don't seem to notice that new materials are driving a second, industrial revolution of iPads, drones and other portable devices. From the perspective of a US citizen, it is significant that the US is being dislodged from the driving seat of that revolution.

Little that was done in Obama's first term, or said in this year's election campaign, will address that prospect. Both candidates talked as though rescuing old industries and fixing the national finances will, in themselves, restore America's economic and industrial primacy. But the data, even from before the 2008 crash, disproves that. The US government would need to be far more proactive if it was to match the energy that emerging nations in Asia, particularly, are applying to building up research competence.

An even greater disappointment of Obama's first term was its failure to act on global warming. Under President George W. Bush, Democrats, in opposition, made a big thing of pursuing 'evidence-based policy' but in office, the administration has supported additional energy research through schemes such as the $\$ 120$ million research hub awarded to Argonne National Laboratory in Illinois, announced on 30 November 2012. But apart from that, the administration has failed to face up to the challenge of climate change even rhetorically, never mind in terms of policy substance.

There have been some rumblings that this might change during the second term. Chu, Holdren and others should be let off the leash on this, to publicly confront those who deny climate change and who have come to pervade US discourse on the issue. However the first act of Obama's second term in this area - his 27 November signing of a law that will exempt US airlines from the European Union carbon-trading scheme is not auspicious in this regard.

Nor is the fiscal outlook for the next four years. Large scientific facilities in the US are ageing, and its public universities are in crisis. Although the funding opportunities, open research culture and wider lifestyle of the US remain intensely attractive to young scientists, it is now only one of several global locations that may appeal to them. Obama's re-election, on some readings, was a victory for America's natural optimism. But there is nothing that the president can do to restore the research hegemony that the US enjoyed in the second half of the twentieth century.

\footnotetext{
References

1. Nature Mater. 7, 923 (2008).

2. The Royal Society Knowledge, Networks and Nations: Global Scientific Collaboration in the $21^{\text {st }}$ Century (2011); http://royalsociety.org/events/2011/knowledge-networks-nations 3. Thomson Reuters Global Research Report: Materials Science and Technology (June, 2011); http://researchanalytics. thomsonreuters.com/grr
} 